\title{
The Prevalence of Type D Personality in a Trinidadian Cardiac Population \\ TMR Changoor ${ }^{1,2}$, G Hutchinson ${ }^{1}$
}

\begin{abstract}
Objective: The current study investigated the prevalence of Type D personality in persons with selfreported cardiovascular disease and the interactions of Type D personality, reported cardiovascular disease and gender in a Trinidadian cardiac population.

Methods: Between June 2009 and August 2009, 425 participants were recruited from the Eric Williams Medical Sciences Complex (EWMSC) Heart Clinic and all the participants completed the Type D Scale. Clinical and demographic variables were obtained from the sociodemographic questionnaire.

Results: Forty-two per cent of participants with self-reported cardiovascular disease were identified as Type D as compared to $26 \%$ of participants who did not report having a cardiovascular illness. The odds ratio indicated individuals identified with Type D personality are 2.0 times more likely to report having cardiovascular disease and females with cardiac disease are 1.6 times more likely to be identified with Type D personality as compared to males.

Conclusions: Previous studies suggest Type D personality is a risk factor for adverse prognosis in the cardiac population, therefore future research examining the link between Type D personality and cardiovascular disease is warranted.
\end{abstract}

Keywords: Cardiovascular disease, gender, myocardial infarction, Type D personality

\section{Prevalencia de la Personalidad de Tipo D en una Población Cardíaca Trinitense} TMR Changoor ${ }^{1,2}$, G Hutchinson ${ }^{1}$

\begin{abstract}
RESUMEN
Objetivo: El presente estudio investigó la prevalencia de la personalidad tipo $D$ en personas con enfermedades cardiovasculares autoreportadas, así como las interacciones de la personalidad de tipo $D$, las enfermedades cardiovasculares reportadas, y el género en una población cardiaca de Trinidad y Tobago.

Métodos: Entre junio y agosto de 2009, 425 participantes fueron reclutados de la Clínica Cardiológica del complejo de Ciencias Médicas Eric Williams (EWMSC), y todos los participantes llenaron el cuestionario de la Escala de Tipo D. Las variables demográficas y clínicas fueron obtenidas del cuestionario sociodemográfico.

Resultados: Cuarenta y dos por ciento de los participantes con enfermedad cardiovascular autoreportada, fueron identificados como tipo D, en comparación con el $26 \%$ de los participantes que no reportó tener una enfermedad cardiovascular. El cociente de probabilidades (odds-ratio) indicó que los individuos identificados con personalidad de tipo D son 2.0 veces más propensos a reportar su enfermedad cardiovascular, y las mujeres con enfermedad cardiaca presentan 1.6 veces más probabilidades de ser identificadas con personalidad tipo D en comparación con los varones.

Conclusiones: Estudios previos sugieren que la personalidad de tipo $D$ es un factor de riesgo que apunta a una prognosis adversa en la población cardiaca. Por lo tanto, las investigaciones futuras que examinen el vínculo entre la personalidad de tipo D y las enfermedades cardiovasculares tienen un lugar asegurado.
\end{abstract}

From: ${ }^{1}$ Department of Clinical Medical Sciences, Faculty of Medical Sciences, The University of the West Indies, St Augustine, Trinidad and Tobago and ${ }^{2}$ School of Kinesiology and Health Science, Faculty of Health, York University, Toronto, Ontario, Canada.
Correspondence: TMR Changoor, School of Kinesiology and Health Science, York University, 341 Norman Bethune College, 4700 Keele St, Toronto, Ontario M3J 1P3, Canada. E-mail: tinachangoor@gmail.com 
Palabras claves: Enfermedades cardiovasculares, infarto del miocardio, género, personalidad de tipo D

West Indian Med J 2013; 62 (5): 469

\section{INTRODUCTION}

Smoking, hypertension, diabetes mellitus, age and gender have long been identified as traditional biological risk factors for the development of cardiac illness. In addition to these common risk factors, psychological and psychosocial factors such as depression (1), anxiety $(2,3)$, low social support (4), chronic life stress (3) and personality (5-7) have also been associated with the incidence and progression of heart disease.

With regard to the possible role of personality factors in health and disease, an important question is whether or not various diseases are indeed associated with particular personalities and if so, does personality play a causal role in disease or are certain aspects of personality the result of disease processes? Research into the role of personality predictors in cardiac health and disease has gained momentum over the past two decades and the accumulating evidence is not inconsistent with a causal role for personality $(2,8)$. The idea that person variables can influence particular health and disease outcomes is becoming more readily accepted with findings suggesting that certain personality clusters can influence the likelihood of experiencing adverse cardiac events $(5-7,9)$.

In the last 15 years, a new personality construct, Type D personality also known as the "distressed" personality, has surfaced as a potential moderator of the health status of cardiac patients (10). Type D personality is the joint tendency to experience negative affectivity (NA) and social inhibition [SI] (11). Negative affectivity is the tendency to experience increased distress across time and situations, and SI is the tendency to inhibit the expression of negative emotions in social interactions (11). Individuals identified with high NA experience feelings of dysphoria or depression, anxiety, irritability, anger and have a negative view of themselves (12). Individuals with high SI feel inhibited, tense, uncomfortable and insecure with others and are less likely to share their negative feelings for fear of rejection or disapproval (12).

Findings show that having a Type D personality can predict adverse health outcomes in coronary artery disease (CAD) and it may serve as a potential risk factor that is at least equivalent, in importance, to other conventional risk factors used in the prognosis of coronary heart disease [CHD] $(5,13-15)$. A 2004 study which investigated the impact of Type D personality on prognosis at nine month's follow-up in 875 consecutive unselected ischaemic heart disease (IHD) patients who were treated with stents found that patients with Type D personality were at an increased risk of death and myocardial infarction (MI) at nine months when compared to patients without Type D personality (16). The risk associated with Type D personality was also found to be on par with that of traditional biomedical risk factors such as previous MI, hypertension, hypercholesterolaemia, diabetes mellitus and smoking status (16).

Using a between-subjects design, another study examined the variability in Type D personality following cardiac rehabilitation, as well as whether Type D personality was a determinant of health status in patients attending cardiac rehabilitation. The prevalence of Type D personality was found to be $26.6 \%$. In addition, no differences were found between Type D and non-Type D patients on baseline demographic and clinical characteristics. Type D patients reported poorer health status prior to and after attending a cardiac rehabilitation programme compared to non-Type D patients. This study provided evidence for the stability of Type D personality and the findings showed that the effect of Type D personality on health status was not only statistically significant but also clinically relevant (14).

The risks that are associated with Type D personality highlight the importance of examining these factors in those who are at an elevated risk for cardiac events (15). The objective of the current study was to investigate the prevalence of Type D personality in persons with self-reported cardiovascular disease (CVD) in a Trinidadian population. Following previous findings, it is expected that there will be a higher prevalence of Type $\mathrm{D}$ personality among persons who report having CVD as compared to persons without a self-reported cardiac illness. For the purpose of the present study, the following diagnoses were included in the definition of CVD coronary artery disease (CAD), coronary heart disease (CHD), coronary heart failure (CHF), ischaemic heart disease (IHD), acute coronary syndrome (ACS), myocardial infarction (MI) and angina.

\section{SUBJECTS AND METHOD}

The study comprised 425 participants, 217 (51.1\%) females and 208 (48.9\%) males who were recruited from June 2009 to August 2009 at the Eric Williams Medical Sciences Complex (EWMSC) Heart Clinic. Participants included EWMSC patients with clinic appointments as well as relatives and/or friends accompanying the patients. Persons in the clinic were approached and informed about the study and asked for their consent to participate. Individuals with and without a selfreported cardiovascular illness were included in the study. Information pertaining to cardiac illness was obtained from the sociodemographic questionnaire. The exclusion criteria were self-report of a psychotic disorder and the inability to understand or read English. Participants' ages ranged from 16 to 87 years with a mean (SD) age of 54.4 years (13.9). The race/ethnicity of the participants was: 226 (53.2\%) Indian, 107 (25.2\%) African, 89 (20.9\%) Multiracial, 2 
$(0.5 \%)$ European and $1(0.2 \%)$ Hispanic. Ethics approval was obtained from the ethics committee of The Faculty of Medical Sciences at the University of the West Indies, St Augustine.

\section{Type D personality}

The Type D Scale (DS14) was administered to assess Type D personality. The DS14 is a 14-item questionnaire which comprises two subscales, NA and SI, with each subscale consisting of seven items (11). The DS14 was designed to identify patients who are at risk for the clustering of these factors, NA and SI. Both of the DS14 subscales, NA and SI, have demonstrated high internal consistency with Cronbach's alpha coefficients of 0.88 and 0.86 and item-total correlations between 0.52 and 0.75 (11). Factor analysis has confirmed the structural validity of the DS14 in a sample of 135 cardiac rehabilitation patients (11). The DS14 subscales have been found to be stable over a three-month period $(r=0.82 / 0.72)$, and are independent of mood and health status (11). Factor analysis of change scores confirmed that changes in personality scores were distinctly different from changes in mood/ health status indicating that scores on the DS14 were not mood state-dependent but were stable over time (11). A study in post-MI patients confirmed that Type D is not confounded by disease severity and mood states and that Type D personality was stable during an 18 -month period $(17,18)$. Evidence suggests the sensitivity and specificity of the DS14 is adequate and is equally applicable in other nationalities (11). The instrument has a five-point Likert scale, ranging from 0 (false) to 4 (true). A standardized cut-off score $\geq 10$ on both subscales is used to classify individuals with a Type D personality (11). The cut-off score of $\geq 10$ for both subscales has been confirmed by means of Item Response Theory as the most optimal in samples from the general population, patients with coronary artery disease and persons with hypertension (19).

An independent quasi-experimental research design was applied. One-way independent analysis was carried out on the 425 participants (the general sample). Participants were dichotomized into two groups, those who reported 'yes' to having CVD and those who did not report having CVD. These two groups (the CVD group and the non-CVD group) were created for independent sample analysis. The CVD group consisted of 273 participants, 136 (49.8\%) females and $137(50.2 \%)$ males. The participants' ages ranged from 16 to 87 years with a mean (SD) age of 57 years (12.9). The race/ethnicity of the 273 participants was: $160(58.6 \%)$ Indian, 57 (20.9\%) African, 53 (19.4\%) Multiracial, 2 (0.7\%) European and $1(0.4 \%)$ Hispanic. The non-CVD group consisted of 152 participants, $81(53.3 \%)$ females and 71 $(46.7 \%)$ males. The participants' ages ranged from 16 to 80 years with a mean (SD) age of 49.9 years (14.4). The race/ ethnicity of the 152 participants was: 66 (43.4\%) Indian, 50 (32.9\%) African and 36 (23.7\%) Multiracial. Additionally, a third group consisting of participants who reported having experienced an MI (the MI group) was created for independent sample analysis. The MI group consisted of 172 participants, 73 (42.4\%) females and 99 (57.6\%) males. The participants' ages ranged from 16 to 84 years with a mean (SD) age of 57.9 years (11.3). The race/ethnicity of the 172 participants was: 107 (62.2\%) Indian, 34 (19.8\%) African, 29 (16.9\%) Multiracial, 1 (0.6\%) European and $1(0.6 \%)$ Hispanic.

The Kolmogorov-Smirnov test indicated the sample groups were all significantly $(p<0.05)$ different from a normal distribution; therefore non-parametric tests were used for the statistical analysis. Variables included the measure of personality (Type D personality construct), self-reported CVD, self-reported MI and gender. Type D personality construct was categorized as either having a Type D personality (identified by a score of $\geq 10$ on both subscales, NA and SI) or not having a Type D personality.

Two-way interactions between the Type D personality measure and self-reported CVD, self-reported MI and gender were examined using the Pearson $\chi^{2}$ statistic. Loglinear analysis was conducted to analyse three-way interactions between these variables. The effect size was assessed using the odds ratio. All $p$-values were one-tailed, and $p$-values less than 0.05 were considered statistically significant. All analyses were conducted using SPSS for Windows, version 12.0 .

\section{RESULTS}

The number of participants identified with Type D personality for the sample groups were: $154(36.2 \%)$ in the general sample $(\mathrm{n}=425), 114(41.8 \%)$ in the CVD group, 70 $(40.7 \%)$ in the MI group and $40(26.3 \%)$ in the non-CVD group. Table 1 displays the percentages for the reported clinical characteristics and Type D personality in males and females for the sample groups. In the general sample, there was a significant interaction between Type $\mathrm{D}$ and reported CVD, $\chi^{2}(1, \mathrm{n}=425)=10.08, p$ (one-tailed) $<0.01$. Table 2 displays the frequencies for the two-way interactions between Type D personality and CVD participants and Type D personality and non-CVD participants. Based on the odds ratio, individuals with Type $\mathrm{D}$ were 2.0 times more likely to report having CVD. Individuals not identified as Type D were 0.5 times as likely to report having CVD.

In the general sample, there was a significant interaction between Type $\mathrm{D}$ and gender, $\chi^{2}(1, \mathrm{n}=425)=5.27, p$ (one-tailed) $<0.05$. Table 3 displays the frequencies for the interactions between Type D personality and gender in the general sample. Based on the odds ratio, females were 1.6 times more likely to have Type D personality. Males were 0.6 times as likely to have Type D personality. Loglinear analysis revealed that the three-way interaction between reported CVD, Type D personality and gender was significant. The Pearson Chi-square for this model was $\chi^{2}(0)=0$, $p=1$, which indicated that the highest-order interaction (CVD x Type D x gender) was significant, $\chi^{2}(1)=4.95, p<$ 
Table 1: Percentages for clinical characteristics and Type D personality in males and females for the sample groups

\begin{tabular}{|c|c|c|c|}
\hline $\begin{array}{l}\text { General sample } \\
(n=425)\end{array}$ & Characteristics & $\begin{array}{c}\text { Males }(n=208) \\
\text { n }(\%)\end{array}$ & $\begin{array}{c}\text { Females }(n=217) \\
n(\%)\end{array}$ \\
\hline & Cardiovascular diagnosis & $137(65.9)$ & $136(62.7)$ \\
\hline & Myocardial infarction & 99 (47.6) & 73 (33.6) \\
\hline & Type D personality & $64(30.8)$ & $90(41.5)$ \\
\hline \multirow{3}{*}{$\begin{array}{l}\text { Cardiovascular } \\
\text { disease group } \\
(\mathrm{n}=273)\end{array}$} & & $\begin{array}{c}\text { Males }(\mathrm{n}=137) \\
\mathrm{n}(\%)\end{array}$ & $\begin{array}{c}\text { Females }(\mathrm{n}=136) \\
\mathrm{n}(\%)\end{array}$ \\
\hline & Myocardial infarction & $99(72.3)$ & $73(53.7)$ \\
\hline & Type D personality & $44(32.1)$ & $70(51.5)$ \\
\hline \multirow{2}{*}{$\begin{array}{l}\text { Myocardial } \\
\text { infarction group } \\
(\mathrm{n}=172)\end{array}$} & & $\begin{array}{c}\text { Males }(\mathrm{n}=99) \\
\mathrm{n}(\%)\end{array}$ & $\begin{array}{c}\text { Females }(\mathrm{n}=73) \\
\mathrm{n}(\%)\end{array}$ \\
\hline & Type D personality & $33(33.3)$ & $37(50.7)$ \\
\hline \multirow{2}{*}{$\begin{array}{l}\text { Non-cardiovascular } \\
\text { disease group } \\
(\mathrm{n}=152)\end{array}$} & & $\begin{array}{c}\text { Males }(\mathrm{n}=71) \\
\mathrm{n}(\%)\end{array}$ & $\begin{array}{c}\text { Females }(\mathrm{n}=81) \\
\mathrm{n}(\%)\end{array}$ \\
\hline & Type D personality & $20(28.2)$ & $20(24.7)$ \\
\hline
\end{tabular}

Table 2: Interactions between Type $\mathrm{D}$ personality and cardiovascular disease (CVD) and non-cardiovascular disease (non-CVD) participants

\begin{tabular}{|c|c|c|c|c|c|c|c|c|c|}
\hline $\begin{array}{c}\text { Type D } \\
\text { personality }\end{array}$ & & $\begin{array}{c}\text { CVD } \\
\text { participants }\end{array}$ & $\begin{array}{c}\text { non-CVD } \\
\text { participants }\end{array}$ & Total & $\begin{array}{c}\text { Type D } \\
\text { personality }\end{array}$ & & Male & Female & Total \\
\hline \multirow[t]{3}{*}{ Yes } & Count & 114 & 40 & 154 & Yes & Count & 64 & 90 & 154 \\
\hline & $\begin{array}{l}\% \text { within Type D } \\
\text { personality }\end{array}$ & 74.0 & 26.0 & 100.0 & & $\begin{array}{l}\% \text { within Type D } \\
\text { personality }\end{array}$ & 41.6 & 58.4 & 100.0 \\
\hline & $\%$ of total & 26.8 & 9.4 & 36.2 & & $\%$ of total & 15.1 & 21.2 & 36.2 \\
\hline \multirow[t]{3}{*}{ No } & Count & 159 & 112 & 271 & No & Count & 144 & 127 & 271 \\
\hline & Expected count & 174.1 & 96.9 & 271.0 & & Expected count & 132.6 & 138.4 & 271.0 \\
\hline & $\begin{array}{l}\% \text { within Type D } \\
\text { personality }\end{array}$ & 58.7 & 41.3 & 100.0 & & $\begin{array}{l}\% \text { within Type D } \\
\text { personality }\end{array}$ & 53.1 & 46.9 & 100.0 \\
\hline \multirow[t]{5}{*}{ Total } & Count & 273 & 152 & 425 & Total & Count & 208 & 217 & 425 \\
\hline & Expected count & 273.0 & 152.0 & 425.0 & & Expected count & 208.0 & 217.0 & 425.0 \\
\hline & $\begin{array}{l}\% \text { within Type D } \\
\text { personality }\end{array}$ & 64.2 & 35.8 & 100.0 & & $\begin{array}{l}\% \text { within Type D } \\
\text { personality }\end{array}$ & 48.9 & 51.1 & 100.0 \\
\hline & $\begin{array}{l}\% \text { within CVD and } \\
\text { non-CVD }\end{array}$ & 100.0 & 100.0 & 100.0 & & $\begin{array}{l}\% \text { within participant's } \\
\text { gender }\end{array}$ & 100.0 & 100.0 & 100.0 \\
\hline & $\%$ of total & 64.2 & 35.8 & 100.0 & & $\%$ of total & 48.9 & 51.1 & 100.0 \\
\hline
\end{tabular}
Interactions between Type D personality and gender in the general
sample 
0.05 . To break down this effect, separate Chi-square tests on Type D personality and gender were performed for the CVD participants and the non-CVD participants. For CVD participants there was a significant interaction between Type $\mathrm{D}$ and gender, $\chi^{2}(1, \mathrm{n}=273)=10.51, p($ one-tailed $)<0.01$. Table 4 displays the frequencies for the interactions between

Table 4: Interactions between Type D personality and gender among cardiovascular disease (CVD) participants

\begin{tabular}{|c|c|c|c|c|}
\hline $\begin{array}{c}\text { Type D } \\
\text { personality }\end{array}$ & & Male & Female & Total \\
\hline \multirow[t]{5}{*}{ Yes } & Count & 44 & 70 & 114 \\
\hline & Expected count & 57.2 & 56.8 & 114.0 \\
\hline & $\begin{array}{l}\% \text { within Type D } \\
\text { personality }\end{array}$ & 38.6 & 61.4 & 100.0 \\
\hline & $\begin{array}{l}\% \text { within participant's } \\
\text { gender }\end{array}$ & 32.1 & 51.5 & 41.8 \\
\hline & $\%$ of total & 16.1 & 25.6 & 41.8 \\
\hline \multirow[t]{5}{*}{ No } & Count & 93 & 66 & 159 \\
\hline & Expected count & 79.8 & 79.2 & 159.0 \\
\hline & $\begin{array}{l}\% \text { within Type D } \\
\text { personality }\end{array}$ & 58.5 & 41.5 & 100.0 \\
\hline & $\begin{array}{l}\% \text { within participant's } \\
\text { gender }\end{array}$ & 67.9 & 48.5 & 58.2 \\
\hline & $\%$ of total & 34.1 & 24.2 & 58.2 \\
\hline \multirow[t]{5}{*}{ Total } & Count & 137 & 136 & 273 \\
\hline & Expected count & 137.0 & 136.0 & 273.0 \\
\hline & $\begin{array}{l}\% \text { within Type D } \\
\text { personality }\end{array}$ & 50.2 & 49.8 & 100.0 \\
\hline & $\begin{array}{l}\% \text { within participant's } \\
\text { gender }\end{array}$ & 100.0 & 100.0 & 100.0 \\
\hline & $\%$ of total & 50.2 & 49.8 & 100.0 \\
\hline
\end{tabular}

Type D and gender among the CVD participants. The odds ratio indicated that females were 2.2 times more likely to have Type D personality. Males were 0.4 times as likely to have a Type D personality. For the non-CVD participants, the interaction between Type D and gender was not significant, $\chi^{2}(1, \mathrm{n}=152)=0.24, p$ (one-tailed $)=0.38$.

In the MI group, there was a significant interaction between Type $\mathrm{D}$ and gender, $\chi^{2}(1, \mathrm{n}=172)=5.24, p$ (onetailed $)<0.05$. The odds ratio indicated females were 2.1 times more likely to have Type D personality. Males were 0.5 times as likely to have a Type D personality. However, loglinear analysis did not reveal that the three-way interaction between MI, Type D and gender was significant, $\chi^{2}(1$, $\mathrm{n}=172)=3.45, p=0.06$.

\section{DISCUSSION}

In the current study, there was a significant interaction between Type D personality and self-reported CVD. Individuals identified with Type D personality were two times more likely to report having CVD. The prevalence of Type D personality was $36.2 \%$ among the 425 participants, $41.8 \%$ in the CVD group, $40.7 \%$ in the MI group and $26.3 \%$ in the non-CVD group. These findings support the hypothesis that there is a higher prevalence of Type $\mathrm{D}$ personality among persons who report having CVD as compared to persons without a self-reported cardiac illness. These findings also fall in line with previous studies showing that the prevalence of Type D personality in the general population varies between 13\% and $25 \%$ and between $26 \%$ and $53 \%$ in the cardiac population (2).

The present study found females were more likely to have Type $\mathrm{D}$ personality as compared to males. Loglinear analysis indicated the three-way interaction between reported CVD, Type D personality and gender was significant. Females with reported CVD were more likely to have Type D personality as compared to males with reported CVD. In the non-CVD group, the interaction between Type D personality and gender was not significant, indicating that females were no more likely to have Type D personality than males. Loglinear analysis did not reveal that the three-way interaction between MI, Type D personality and gender was significant but it should be noted that the significance of this three-way interaction was $p=0.06$. Perhaps if the sample of MI participants was larger a significant finding might have been more likely.

Literature on gender-related risk profiles for CVD is limited due to a lack of studies in gender-balanced populations, as well as a lack of randomized clinical studies with a larger number of women $(20,21)$ and so the differences found between females and males cannot be fully understood. The possibility exist that because individuals with Type D personality are more likely to report high depressive symptomatology (22) and the rate of depression in women is twice that of men in the cardiac patient population (23), then perhaps depressive symptoms which fall under the scope of NA may contribute to increasing the likelihood of females being diagnosed with CVD. It has been suggested that gender role-related stressors such as low socio-economic status and associated psychological attributes such as emotionfocussed coping styles and interpersonal orientation render females to be more vulnerable to depression than males (20, 21). As well, the differences in endocrine stress reactions between women and men may leave women more susceptible to depression than men $(20,21)$. Subsequently, the increased vulnerability to depression increases the likelihood that females will become diagnosed with CVD $(20,21)$.

The findings of the present study need to be interpreted with some caution because there were several limitations in the study design. Firstly, cause and effect could not be determined because random sampling techniques were not employed and the study sample was not representative of a normal population. Secondly, the study relied on participants self-reports on medical conditions rather than on clinical assessments or reports from medical providers. Therefore, 
the study lacked clinical significance on the reported measures for CVD diagnosis and MI. Thirdly, the assessment of Type D personality was based on the self-report measure, the DS14. Findings support the use of the DS14 in clinical research and factor analytic and reliability criteria provide support for its two-factor structure and internal consistency (11). However, although evidence suggests the sensitivity and specificity of the DS14 is adequate and is equally applicable in other nationalities, the instrument was developed in Belgian patients and it has not been examined in a Trinidadian population (11). Therefore, more research is needed to determine the cross-cultural validity of Type D personality and the DS14 in a Trinidadian population. Fourthly, there was no control for lifestyle factors such as diet, obesity and behavioural risk factors such as smoking and alcohol consumption. Fifthly, the relatively small number of participants and clinical events implies the statistical power might have been too low and therefore might have contributed to some of the insignificant findings.

The existing literature suggests that traits may exert a more stable effect on cardiac outcome than other individual difference variables routinely included in cardiovascular research (24). Moreover, evidence is accumulating that the distressed personality (Type D) is a risk factor across CVD patient groups (25). In these patient groups, Type D personality has been associated with a 2-5 fold increase in risk for adverse prognosis, as well as an increase in symptoms of depression, independent of traditional biomedical risk factors such as disease severity (25). Research suggests Type D personality is a risk factor that is here to stay (25) and so future research examining Type D personality and cardiac illnesses in a Trinidadian population is warranted.

\section{REFERENCES}

1. Barth J, Schumacher M, Herrmann-Lingen C. Depression as a risk factor for mortality in patients with coronary heart disease: a metaanalysis. Psychosom Med 2004; 66: 802-13.

2. Kupper N, Denollet J. Type D personality as a prognostic factor in heart disease: assessment and mediating mechanisms. J Pers Assess 2007; 89: 265-76.

3. Rozanski A, Blumenthal JA, Kaplan J. Impact of psychological factors on the pathogenesis of cardiovascular disease and implications for therapy. Circulation 1999; 99: 2192-217.

4. Orth-Gomér K, Rosengren A, Wilhelmsen L. Lack of social support and incidence of coronary heart disease in middle-aged Swedish men. Psychosom Med 1993; 55: 37-43.

5. Denollet J, Sys SU, Stroobant N, Rombouts H, Gillebert TC, Brutsaert DL. Personality as independent predictor of long-term mortality in patients with coronary heart disease. Lancet 1996; 347: 417-21.

6. Denollet J, Vaes J, Brutsaert DL. Inadequate response to treatment in coronary heart disease: adverse effects of type D personality and younger age on 5-year prognosis and quality of life. Circulation 2000; 102: $630-5$.
7. Lachar BL. Coronary-prone behavior. Type A behavior revisited. Tex Heart Inst J 1993; 20: 143-51.

8. Friedman HS, Booth-Kewley S. The "disease-prone personality". A meta-analytic view of the construct. Am Psychol 1987; 42: 539-55.

9. Scheier MF, Bridges MW. Person variables and health: personality predispositions and acute psychological states as shared determinants for disease. Psychosom Med 1995; 57: 255-68.

10. Denollet J, Sys SU, Brutsaert DL. Personality and mortality after myocardial infarction. Psychosom Med 1995; 57: 582-91.

11. Denollet J. DS14: standard assessment of negative affectivity, social inhibition, and Type D personality. Psychosom Med 2005; 67: 89-97.

12. Tulloch H, Pelletier R. Does personality matter after all? Type D personality and its implications for cardiovascular prevention and rehabilitation. Curr Issues Card Rehab Prevention 2008; 16: 2-4.

13. Denollet J, Pedersen SS, Vrints CJ, Conraads VM. Usefulness of type D personality in predicting five-year cardiac events above and beyond concurrent symptoms of stress in patients with coronary heart disease. Am J Cardiol 2006; 97: 970-3.

14. Pelle AJ, Erdman RA, van Domburg RT, Spiering M, Kazemier M, Pedersen SS. Type D patients report poorer health status prior to and after cardiac rehabilitation compared to non-type D patients. Ann Behav Med 2008; 36: 167-75.

15. Sher L. Type D personality: the heart, stress, and cortisol. QJM 2005; 93: 323-9.

16. Pedersen SS, Lemos PA, van Vooren PR, Liu TK, Daemen J, Erdman RA et al. Type D personality predicts death or myocardial infarction after bare metal stent or sirolimus-eluting stent implantation: a Rapamycin-Eluting Stent Evaluated at Rotterdam Cardiology Hospital (RESEARCH) registry substudy. J Am Coll Cardiol 2004; 44: $997-$ 1001.

17. de Jonge P, Denollet J, van Melle JP, Kuyper A, Honig A, Schene AH et al. Associations of type-D personality and depression with somatic health in myocardial infarction patients. J Psychosom Res 2007; 63: $477-82$.

18. Martens EJ, Kupper N, Pedersen SS, Aquarius AE, Denollet J. Type-D personality is a stable taxonomy in post-MI patients over an 18-month period. J Psychosom Res 2007; 63: 545-50.

19. Emons WH, Meijer RR, Denollet J. Negative affectivity and social inhibition in cardiovascular disease: evaluating type-D personality and its assessment using item response theory. J Psychosom Res 2007; 63: 27-39.

20. Möller-Leimkühler AM. Gender differences in cardiovascular disease and comorbid depression. Dialogues Clin Neurosci 2007; 9: 71-83.

21. Naqvi TZ, Naqvi SS, Merz CN. Gender differences in the link between depression and cardiovascular disease. Psychosom Med 2005; 67: S1518.

22. Pedersen SS, van Domburg RT, Theuns DA, Jordaens L, Erdman RA. Type $\mathrm{D}$ personality is associated with increased anxiety and depressive symptoms in patients with an implantable cardioverter defibrillator and their partners. Psychosom Med 2004; 66: 714-9.

23. Frasure-Smith N, Lespérance F. Reflections on depression as a cardiac risk factor. Psychosom Med 2005; 67: S19-25.

24. Pedersen SS, Middel B, Larsen ML. The role of personality variables and social support in distress and perceived health in patients following myocardial infarction. J Psychosom Res 2002; 53: 1171-5.

25. Pedersen SS, Denollet J. Is type D personality here to stay? Emerging evidence across cardiovascular disease patient groups. Curr Cardiol Rev 2006; 2: 205-13. 


\section{Appendix: Sociodemographic Questionnaire}

Please take the time to read and answer each question carefully.

1. What is your age?

2. What is your date of birth (date/month/year)?

3. What is your gender?

Male $\quad \square$

Female $\quad \square$

4. What is your race (ie African, Indian, European, Asian, Hispanic, Mixed, Other)?

African

Indian $\quad \square$

European $\quad \square$

Asian $\quad \square$

Hispanic $\quad \square$

Mixed $\quad \square$

Other $\square$ (please specify)

5a. Have you ever been diagnosed as having a cardiovascular (heart) related disease and/or related illness?

Yes $\square \quad$ No $\square$

5b. If yes, please specify the diagnosis/disease.

6a. Have you ever experienced a myocardial infarction (heart attack)? Yes $\square \quad$ No $\square$

6b. If yes, when did it occur (please specify month and year).

7a. Have you ever been diagnosed as having diabetes mellitus?

Yes $\square \quad$ No $\square$

7b. If yes, please specify the diagnosis/disease (ie Type 1, Type 2).

8. Have you ever been diagnosed as having hypertension (high blood pressure)?

Yes $\square \quad$ No $\square$
9. Have you ever been diagnosed as having hypercholesterolaemia (high cholesterol)?

Yes $\square \quad$ No $\square$

10a. Have you ever been diagnosed as having cancer?

Yes $\square \quad$ No $\square$

10b. If yes, please specify the diagnosis/disease.

11a. Do you smoke cigarettes?

Yes $\square \quad$ No $\square$

11b. If yes, how many cigarettes do you smoke in a day?

12a. Have you ever been diagnosed with a Psychotic Disorder?

Yes $\square \quad$ No $\square$

12b. If yes, please specify the diagnosis.

13. What is your marital status?

Married $\quad \square$

Single $\quad \square$

Divorced

Separated

Common-Law

Other $\quad \square$ (please specify)

14. What is your weight? (please specify in pounds [lbs] or kilograms [kgs])

15. What is your height? (please specify in feet, inches, or centimetres)

16. What is your highest school achievement?

17. What is your monthly income? 